\title{
APPARATUS AND METHOD FOR CALCULATING PENETRATION FORCE BY DROP WEIGHT IMPACT TECHNIQUE
}

\author{
${ }^{\star}$ Mohammed H. Khalaf ${ }^{1}$
}

Suhad D. Salman ${ }^{1}$

1) Mechanical Engineering Department, College of Engineering, Mustansiriyah University, Baghdad, Iraq

\begin{abstract}
Because of the limitations that are experienced when trying to perform Charpy and Izod impact tests, the drop weight impact test is preferred over the more conventional impact methods to determine whether the material is brittle or ductile. The drop weight impact technique indicates the conditions under which real-life components would be subject to impact loading. In this study, a drop-weight impact instrument has been designed and manufactured using a dropping weight which impacts the specimens, falls through a perpendicular guide tube with a high range of impact energy levels. Force - deformation and acceleration time graphs, could be determined by using various sensor systems were installed to calculate the impactor's velocity and the magnitude of the impact force. Consequently, the energy absorption of different materials can be measured and the damage resistance could be indicated.
\end{abstract}

Keywords: Drop weight impact test, Manufacturing, Impact method, Composite materials.

\section{Introduction}

Composite materials are commonly being used in structural projects, and they are being used in a variety of engineering industries, such as aerospace, transportation, and building Structures. One of the key reasons for choosing this material is that conventional metal alloys may not always be able to meet the need of the designer, as well as modulus and specific strength with high corrosion and low density [1]. Composites fabricated by the polymeric matrix reinforced by fibres are greatly used and growing fast to become viable alternatives to traditional metal materials in a variety of industrial applications. The composites have lacked the ductility of metals and are unable to absorb impact energy through small local deformations as metals can. In order to use these materials, it is necessary to determine their behaviour and mechanical characteristics [2]. In composites, the toughness property is an essential property, it shows the absorbed energy capacity of the materials. By low impact tests, the absorbed energy could be measured through a tool dropping from a height striking the samples to study the degradation and damage on them [3]. Due to the restrictions of both two popular techniques of low impact tests, Izod and

Charpy, the drop weight impact method has many advantages compared with them. Unlike Izod and Charpy methods, the drop weight impact method has the ability to test based on various types of standards and shapes, even the piece itself, which allows excellent precision. In addition, load-time and absorbed energy-time charts could be drawn, which allow studying the 
failure history and evaluate the damage consequences more accurately [4]. Furthermore, the samples could be tests under any slope. Moreover, different tests can be investigated after drop weight impact tests, like post-impact, compression, etc. tests [5]. Based on the reported studies [6-10], the mechanism guide of the impactor associated with weight could allow dropping the weight with no friction between impactor striker and guides. In addition, a drop-weight impact tester should include supports to guide the sample attachment base [11]. The mechanism guide of the impactor should provide a subsystem to prevent a second impact, to allow more accurate results [12]. Also, variation in height of the drop weight machine permits studied the sample's behaviour under different energy levels.

This study investigated many reported drop weight impact equipment information in the literature [13]. It has been found that there is a lack of detailed design of the manufactured drop weight impact testers, which has boosted to find appropriate solutions for developing drop weight impact test machine. To evaluate the consequences of drop weight impact on the composite materials, a drop-weight impact instrument has been developed that utilize bodies in free falling to test laminated composites, with overcoming existing errors and Adding sensors to increase the accuracy of results.

\section{Materials and Methods:}

The drop weight impact machine was designed and developed in accordance with ASTM D7136 [14] low-velocity impact tester, an international standard. Modelling has been used in REVIT software to assist in the creation of a design that outlines the machine. "Fig. 1", shows the schematic representation of the device's design, with various components. In this study, the device is modelled by Revit software, which is one of the programs of the BIM system (Building Information Modeling). The Revit software is using for creating a model for projects in mechanical, construction, and architectural buildings in a three-dimensional image and linking them with each other. It provides ease and speed of work and the ability to add a large number of details in a clear way with three-dimensional shapes and required measurements of materials.

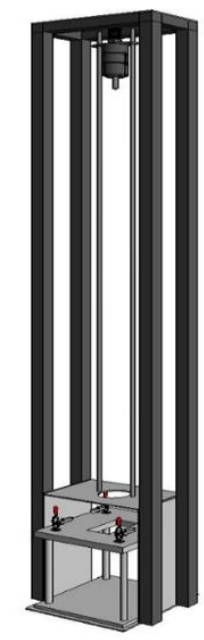

Figure 1. Low-Velocity Impact machine

The principle of the drop weight impact tests is to drop a certain falling weight of a specific height over the samples to be tested through vertical guide which direct it perpendicular to the centre of the sample. According to the standard ASTM D7136, rectangular plates shape are subjected to concentrated weight with hemispherical impactor shape, as shown in "Fig.2". The potential energy of the falling mass would be converted to the kinetic energy when falling weight is released. 


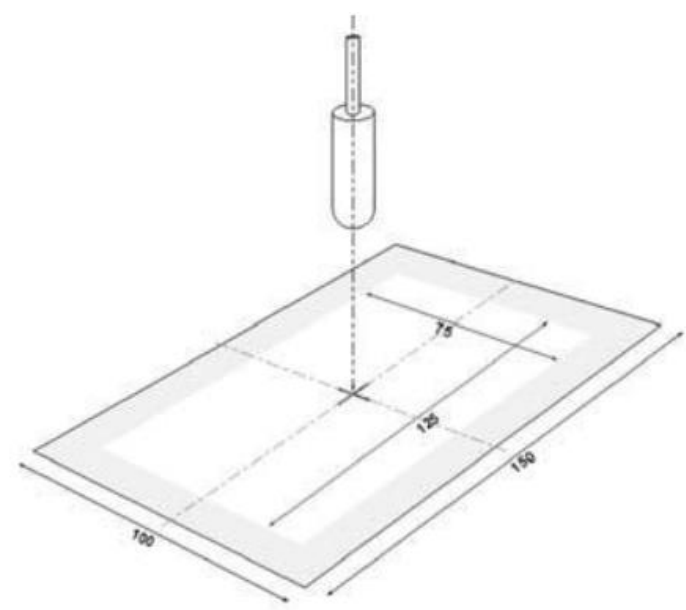

Figure 2. Schematic representation the drop weight impact test per (15).

Unlike the traditional way of measuring energy absorption, the drop weight impact method measures the energy absorption more precisely, by load versus time graphs to illustrate energy absorption history. Furthermore, various failure modes could be studied under low impact load conditions.

Energy released from falling impactor mass is,

$E=m g h$

Where " $\mathrm{E}$ " is energy $(\mathrm{J})$, " $\mathrm{m}$ " is mass of impactor $(\mathrm{kg})$, " $\mathrm{g}$ " is gravity $\left(\mathrm{m} / \mathrm{s}^{2}\right)$, " $\mathrm{h}$ " is height (m).

At every moment, absorbed energy could be calculated by:

$\int F \cdot d y=$ Absorbed Energy

Where " $\mathrm{F}$ " is force, " $\mathrm{y}$ " is displacement.

While the change in kinetic energy is calculated by Eq. 3, shows whole absorbed energy and using for calibration.

$\int F \cdot d y=\frac{1}{2} \cdot m \cdot v_{1}^{2}-\frac{1}{2} \cdot m \cdot v_{2}^{2}$

Where " $\mathrm{m}$ " is mass of impactor, $\mathrm{v}_{1}$ and $\mathrm{v}_{2}$ are impactor velocity before and after impact test.

\section{Experimental work:}

After determining the conceptions and machine dimensions according to the ASTM D7136 Standard, a general view of the machine design procedure has been done. Both fall weight and height of the impactor, as well as apparatus dimensions, have been estimated. Drop weight impact tester include some components like impacting mechanism, fixture systems, elevation system, pneumatic brake/release, and a data collection system, as detailed below:

\subsection{Base of Device}

Two square base plates each one having (300 $\mathrm{mm} \times 300 \mathrm{~mm}$ ) dimension the upper base $25 \mathrm{~mm}$ thick and has a rectangular hole $(125 \times 75) \mathrm{mm}$, while the lower plate has $12 \mathrm{~mm}$ dimension and four rods are connected between them the rod have $25 \mathrm{~mm}$ diameter and $300 \mathrm{~mm}$ long and have four clamps, as illustrated in "Fig. 3".

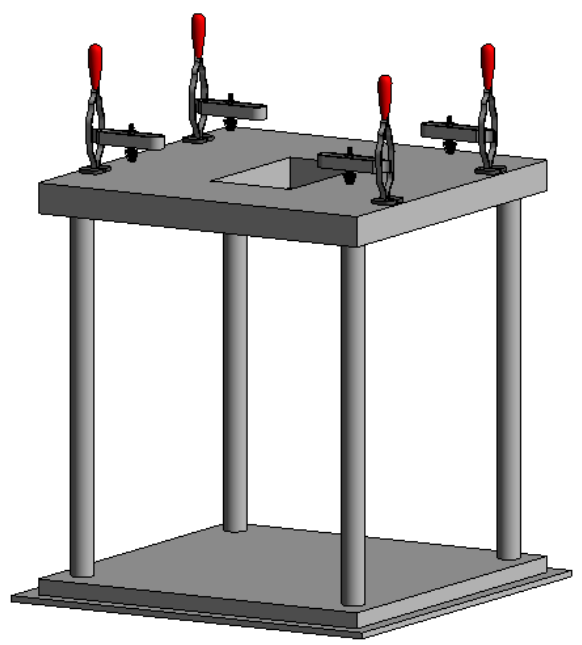

Figure 3. Base of device.

\subsection{Structure Design over the Base}

The structure surrounds the base which has $5 \mathrm{~mm}$ thick and a circle hole of $90 \mathrm{~mm} \emptyset$, as shown in "Fig. 4". 


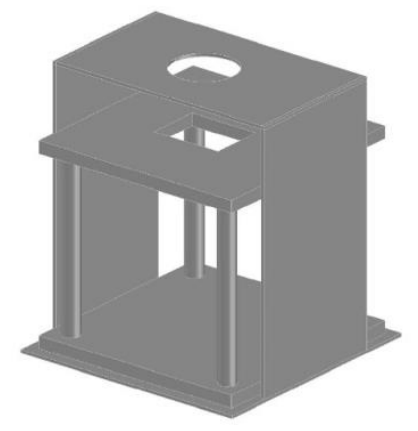

Figure 4. Structure over the base.

\subsection{Guide}

Two stainless steel rods connect with impactor and have $13 \emptyset \mathrm{mm}$ diameter and $2250 \mathrm{~mm}$ long.

\subsection{Impactor}

The impactor striker has a mass of $5.23 \mathrm{~kg}$ and a $16 \mathrm{~mm}$ diameter smooth hemispherical striker tip and a hardness of $82 \mathrm{HRB}$ with stainless steel plate connected with the guide, as shown in "Fig. 5". The hardness test was done for the hemispherical striker tip of the impactor according to the ISO 6508 standards by a united true blue hardness tester machine in the State Company for Inspection and Engineering Rehabilitation (SIER).

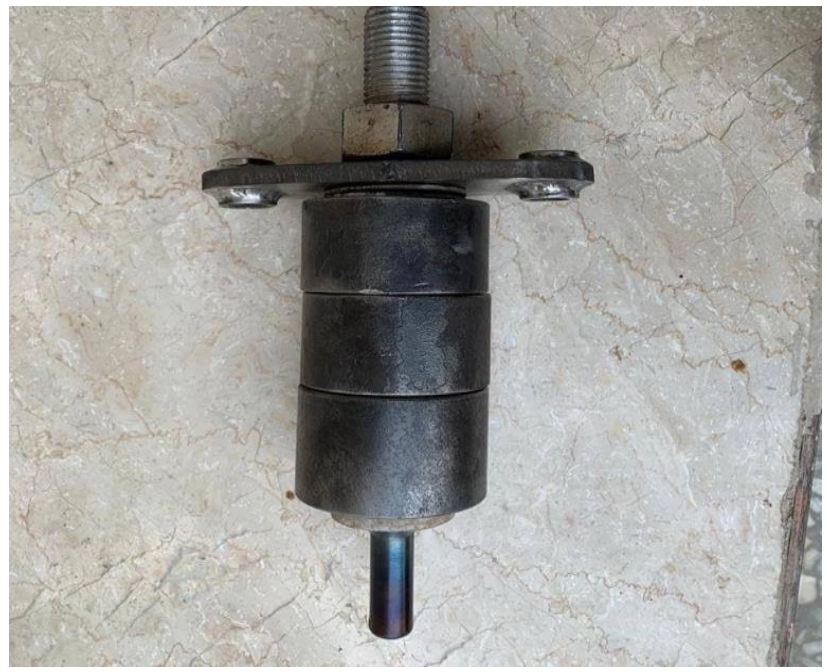

Figure 5. Impactor

\subsection{Impactor Holder}

It was an electromagnet that could hold $20 \mathrm{~kg}$ of weight with the maximum amount of energy. It connects with the motor by chain and sprocket. A hook has been added to this device, to allow using various load weights range for the impactor, by working as equivalent weight, as shown in "Fig. 6". Add to that, four iron shafts have been used to support the device.

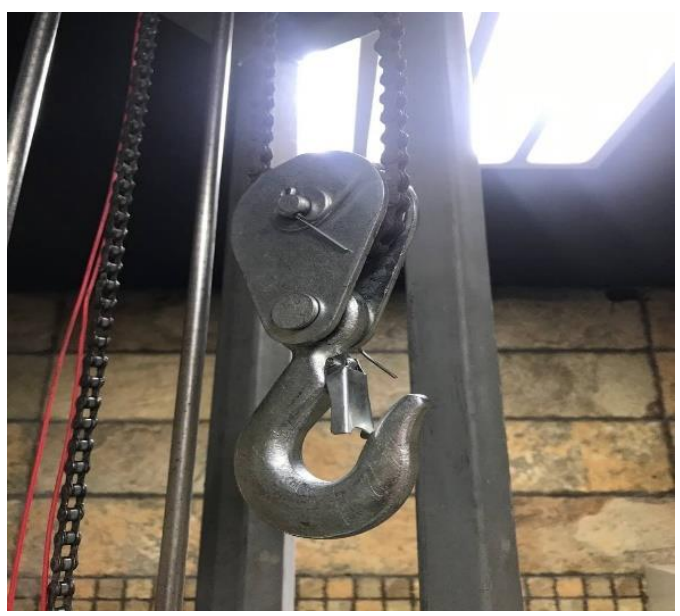

Figure 6. The hook.

\subsection{Box of Power Supply}

The Arduino board, the power supply, and some wires that attached to the sensors are all stored in this box.

\subsection{Stepper Motor}

Electrical motor used to hold and rise the impactor to different heights, by taking the order from computer, as shown in "Fig. 7".

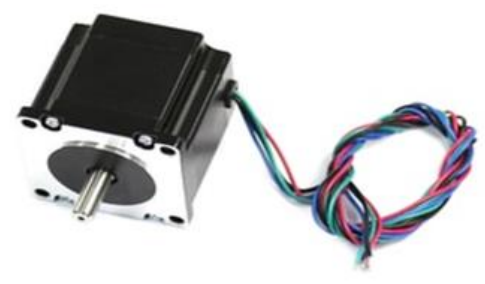

Figure 7. Stepper motor. 


\subsection{F. S. R. (Force Sensitive Resistor) Sensor}

It is placed at the bottom of the sample, used to measure the impact force at the moment of collision, as shown in "Fig. 8".

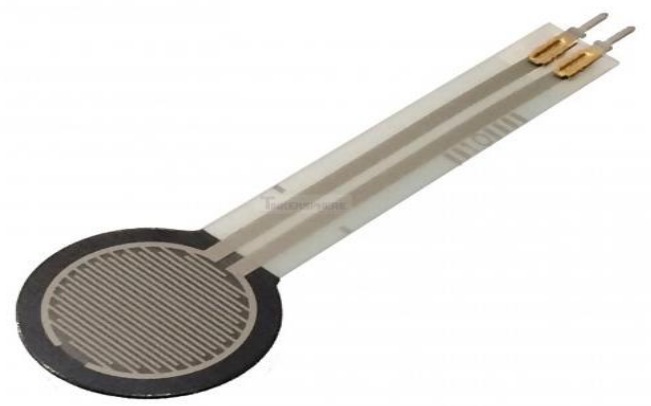

Figure 8. F. S. R. Sensor.

\subsection{Velocity Sensor}

It uses infrared rays and the transmitting and receiving principle to determine the presence of an object at a set distance, as shown in "Fig. 9".

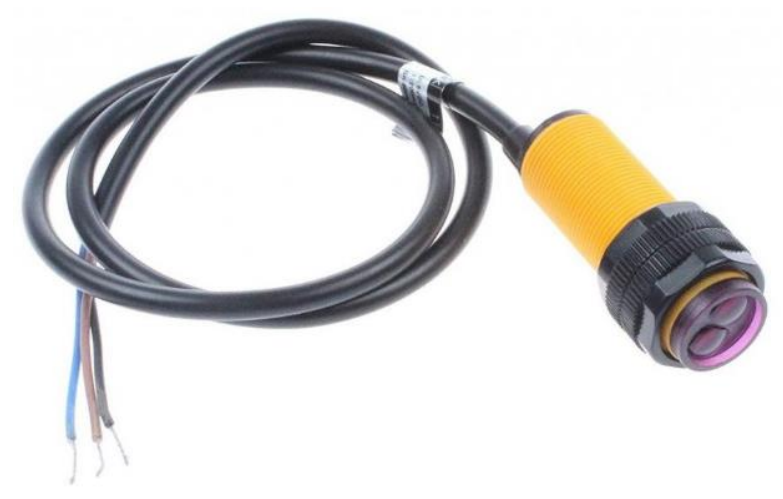

Figure 9. Velocity Sensor.

\subsection{Brake System}

Failure of the impact specimen occurs in two possibilities after drop weight impact; either sample fails by the shock absorber, so impactor striker comes down then stop, or the impactor striker bounce backs after sensing the impactor return by the sensor. In that case, then receiving signal and shock absorber stop the impactor striker to come down again to make a second impact.

\section{Conclusions}

The impact testing machine for falling weights has been manufactured and developed successfully with a high range of impact energy levels. It was able to estimate low impact behaviour by drop weight in order to assess an aspect of damage resistance of composite laminate. After equipment manufacturing and calibration, drop weight impact has been installed and successfully utilized. Impact energy, absorbed energy, velocity of impact, displacement, and another variables could be obtained from this automatic instrument tester.

\section{Acknowledgements}

Authors would like to thank the Ministry of Higher Education and Scientific Research / Iraq and to Mustansiriyah University, College of Engineering / Mechanical Engineering Department, for their scientific assistance and support.

\section{Conflict of Interest}

All authors have participated in (a) conception and design, or analysis and interpretation of the data; (b) drafting the article or revising it critically for important intellectual content; and (c) approval of the final version. This manuscript has not been submitted to, nor is under review at, another journal or other publishing venue.

\section{References}

1. Potter, K., 1997. An introduction to composite pruducts: Design, development and manufacture. Springer-Verlag, New York, 2nd edition.

2. Akin, C. and ŞENEL M., 2010. "An experimental study of low velocity impact response for composite laminated plates". 
Journal of the Institute of Science \& Technology of Dumlupinar U; Issue 21, p77.

3. Hebert, M., Rousseau, C. E and Shukla, A., 2008. "Shock loading and drop weight impact response of glass reinforced polymer composites". Composite Structures, Vol 84, p. 199-208.

4. Keršys, A., keršienė N., and žiliukas A., 2010. "Experimental Research of the Impact Response of E-Glass / Epoxy and Carbon / Epoxy Composite Systems". Materials science, Vol. 16, p.1392-1320

5. Zhang, Y. Johnston, A. Ouellet, S. Williams, K. Boucher, D. and Labonte, S.,2010. "Low-speed impact test for foam supported composite laminates." In Proceedings of the 8th Canada-Japan joint Workshop on Composite Materials, Institute for Aerospace Research, Boucherville, Canada.

6. Ambur, D.R., Prasad, C.B. \& Waters, W.A. (1995). A dropped-weight apparatus for low-speed impact testing of composite structures. Experimental Mechanics, 35(1), 77-82.

7. Gunawan, L., Dirgantara, T. \& Putra, I.S. (2011). Development of a dropped weight impact testing machine. International Journal of Engineering \& Technology, 11(6), 120-126.

8. Shokrieh, MM. Taheri-Behrooz, F., Davaee, A.H., Akhavan, N. \& Abtahi, R. (2002). Drop weight impact tester. Final Report, Iran University of Science and Technology.

9. F. Taheri-Behrooz, M.M. Shokrieh and H.R. Abdolvand, 2013." Designing and manufacturing of a drop weight impact test machine". Engineering Solid Mechanics 1 (2013) 69-76

10. Sharma, R. S. and Raghupathy, V. P., 2011. "Design and fabrication of equipment for low velocity impact testing of composite sandwich panels". Journal of Engineering and Applied Sciences, Vol. 6, p. 22-25.

11. Toropov, AI. \& Grosso, M. (1998). Dynamic calibration of impact test instruments. Journal of Testing and Evaluation, 26(4), 315-319.

12. Madjidi, S., Arnold, W. S., \& Marshall, I. H. (1996). Damage tolerance of CSM laminates subject to low velocity oblique impacts. Composite structures, 34(1), 101116.

13. Mulder, D. (2002). Investigation of Impact Loading on Particulate Filled Resins, BEng Thesis, University of Southern Queensland, Australia.

14. ASTM D 7136/D 7136M-15, (2015). Standard Test Method for Measuring the Damage Resistance of a Fiber-Reinforced Polymer Matrix Composite to a DropWeight Impact Event. ASTM International, West Conshohocken, PA

15. Silva, J.M., Nunes, C. Z., Franco N. and Gamboa P. V., 2011. "Damage tolerant cork based composites for aerospace applications". The Aeronautic Journal, Vol. 15 No. 1171. 